\title{
Study on structural effect of equivalent elastic modulus of columnar jointed rock mass
}

\author{
Zhen Cui ${ }^{1,2, a^{*}}$, Qian Sheng ${ }^{1, b}$, and XianlunLeng ${ }^{1, c}$ \\ ${ }^{1}$ State Key Laboratory of Geomechanics and Geotechnical Engineering, Institute of Rock and Soil \\ Mechanics, Chinese Academy of Sciences, Wuhan, Hubei 430071, China; \\ ${ }^{2}$ PowerChina Huadong Engineering Corporation Limited, Hangzhou, Zhejiang 310014, China. \\ azcui@whrsm.ac.cn, bqsheng@whrsm.ac.cn, ’xlleng@whrsm.ac.cn
}

Keywords: Columnar jointed rock mass, equivalent elastic modulus, structural effect, Jointed Finite Element Method, column irregularity.

\begin{abstract}
Owning to its special geological origin, columnar jointed rock mass is a special kind of geological structure with strong discontinuity and anisotropic. In this paper, influence of structural effect on the equivalent modulus of columnar jointed rock mass is discussed via Jointed Finite Element technique for the Baihetan project. It is noted in this paper that on the transverse plane, more the irregularity of the column is, the higher the equivalent modulus is. And this trend also aggresses with the increase of the column size. Columnar joints rock mass can be regarded as isotropic in the transverse plane. As the joint stiffness linearly increase, the equivalent modulus corresponding basically with the linear increasing. As for the longitudinal plane, more the spacing of the joint set II, the higher the equivalent modulus is. The equivalent modulus reaches its maximum value when the stagger ratio is $50 \%$. Like on the transverse plane, as the joint stiffness linearly increase, the equivalent modulus linearly increase, correspondingly. The results of this paper agree well the existing field observations and 3-d numerical studies. The findings and conclusions of this paper may provide a reference for future studies.
\end{abstract}

\section{Introduction}

Abundant hydropower resources are available in southwest China, where a number of large-scale hydropower plants are currently either under construction or at design stage. Most of those plants are located in rock masses, falling or sliding of rock mass blocks or wedges defined by intersecting structural discontinuities is the most common type of failure, known as the structure effect of the jointed rock mass $[1,2]$. Hence, the influences of the structure effect on the stability of these underground works would be a major geotechnical issue to be addressed during design and construction of these giant hydropower plants.

As a distinctive type of rock mass structure, columnar jointed rock mass are characterized by strong discontinuity and anisotropy [3]. The relationship of the structural characteristics of the columnar joints and the macro equivalent deformation modulus of rock mass are the one of the most interest area in the research of the columnar jointed rock mass.

The Baihetan hydropower plant is located on the Jinsha River in southwest China. It is one of the key elements of China's West-East Electricity Transmission Project and has been classified as a class I project, the most vital rank according to the Chinese code. The project involved the excavation of two large cavern complexes in both the left and right banks. The plant is mainly located in a rock mass of the Upper Emei Mountain Group of Permian age. The rock mass possesses an orientation of $120 \sim 145^{\circ} / 15 \sim 20^{\circ}$ (dip direction/dip angle) and mainly consists of $P_{2} \beta_{2}^{3}, P_{2} \beta_{3}^{1}$, and $P_{2} \beta_{3}^{2}$ stratum, where the existence of large amount of columnar jointed rock mass are detected. Those columnar jointed rock mass are vital to the engineering rock mass classification work, and eventually become a major geological problem of the plant[4].

The columnar jointed rock mass of Baihetan hydropower plants are taken as the research object in this paper. Influence of structural effect on the equivalent modulus of columnar jointed rock mass is to be discussed via Jointed Finite Element technique. The characterization parameters of the 
structural effects are firstly discussed. Then the effect of the structural parameters on the equivalent deformation modulus of the columnar jointed rock mass is studied. Encouraging results were obtained that may serve as technological references for the design of hydropower plant.

\section{Principles}

The main feature of columnar jointed rock masses in Baihetan hydropower project area is that the columnar joints are layer-like developed in Aphanitic Basalt, yet in each layer, the development of columnar joints is not even, the size and length of those rock columns may vary greatly. According to the development characteristics of columnar joints, the columnar jointed rock mass can be divided into three categories[5].

(1) Type I: The density of columnar joints is relatively large. Length of the rock column is approximately $2 \sim 3 \mathrm{~m}$, and 13 25 for the equivalent diameter, as shown in Fig. 1(a). (2) Type II: Length of the rock column would be $0.5 \sim 2.0 \mathrm{~m}$, and the equivalent diameter would be $25 \sim 50 \mathrm{~cm}$, see Fig. 1(b). And (3) Type III: the rock column is not completely formed, and the Length of the rock column is approximately $1.5 \sim 5 \mathrm{~m}$, and $0.5 \sim 2.5$ for the equivalent diameter, as shown in Fig. 1(c).
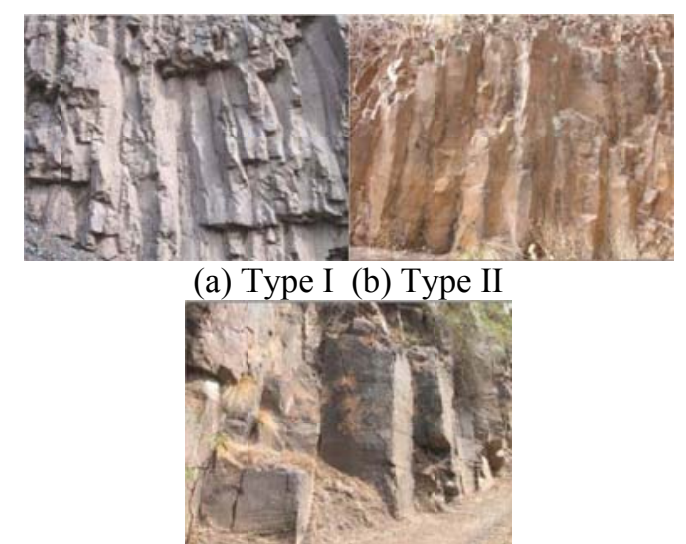

(c) Type III

Fig. 1 Classification of the columnar jointed rock mass of the dam site

Set up the 2d numerical model. In order to calculate and determine the mechanical parameters of columnar jointed rock mass by numerical simulation, the rock mass is firstly abstracted into $2 \mathrm{~d}$ concept model, as shown in Fig. 2. The transverse plane of the rock column is termed as the x-y plane; and the longitudinal axis of the rock column is termed as $\mathrm{z}$ direction. In this way, in $2 \mathrm{~d}$ numerical simulation, the rock mass are analyzed in transverse plane and longitudinal plane, as shown respectively in Fig. 3 and 4.

Traditionally for rock mass models whom possess a large number of joint asi shown in Fig. 3 and 4, the discrete element method is generally believed to be the only practical method. However in common commercial numerical software such as UDEC, the element is often simplified as constant strain with merely one Gauss integration points. Making stress results are relatively low, and affecting the reliability of research results. The introduction of Jointed Finite Element Method (JFEM) made it possible to consider such massive joints in finite element method which possess a relatively high accuracy for stress calculation.JFEM refers to a finite element simulation with the ability to deal with joint network systems. In JFEM, solid element is used to simulate rock matrix, and joint is simulated by contact element. In this paper, the Phase 2 code is used to implement the JFEM analysis. And, to make sure that enough joints were included in the numerical specimen, a relatively large size of $10 \mathrm{~m} \times 10 \mathrm{~m}$ was adopted for the numerical specimen. 


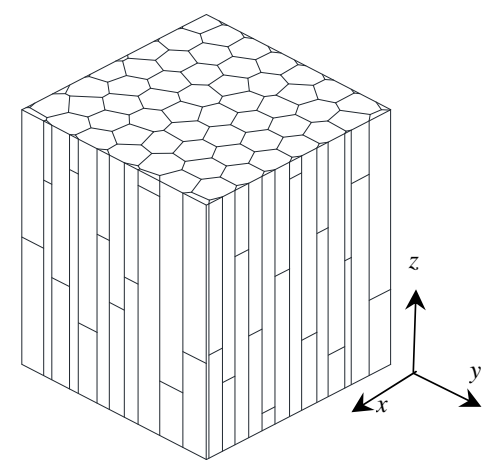

Fig. 2Conceptual model of columnar jointed rock mass

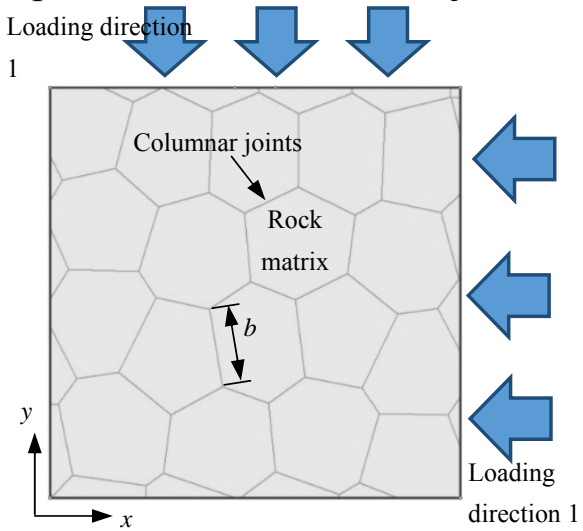

Fig. 32 -d model of the transverse plane

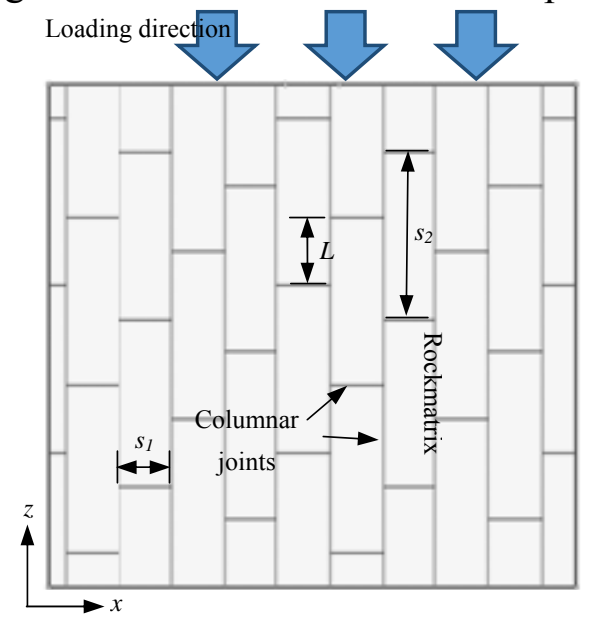

Fig. 4 2-d model of the longitudinal plane

Representative indexes of structure effect in columnar jointed rock mass. In terms of experience, the representative indexes of structure effect in the columnar jointed rock mass obeys some certain mathematic distributions. In the following investigation, columnar jointed rock mass with various structure effect representative indexes are established and numerical tested. In this way the influence of the structure effect indexes on the elastic modulus of the columnar jointed rock mass is addressed.

(1) Transverse plane

The columns on the transverse plane were generated via a Voronoi process [8], hence the two most basic structure effect indexes are mean side length of the column and column irregularity. When considering the existence of the significant anisotropy in the columnar jointed rock mass, loading directions and joint stiffness between columns are also taken as two structure effect indexes.

As for the column irregularity, completely regular hexahedron is taken as the lower limit of the degree of irregularity, while the most possible irregular column that the Phase 2 code can generate is taken as the upper limit of the degree of irregularity. Irregularity has been qualitatively divided into four degrees, i.e. fully regular, regular, moderate regular, and irregular, as shown in Fig. 5. 


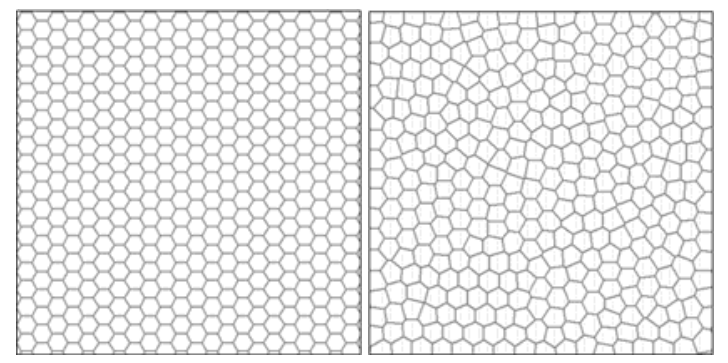

(a) fully regular(b) regular

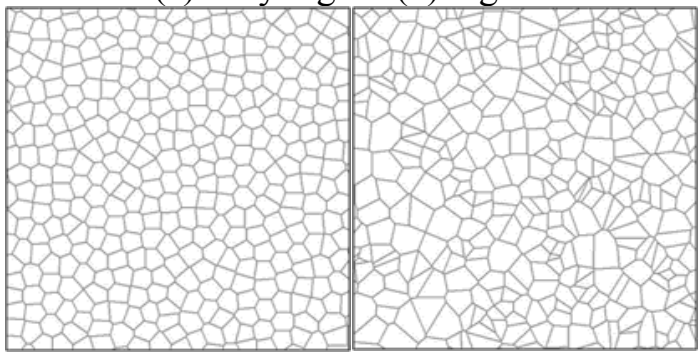

(c) moderate regular(d) irregular

Fig. 5 Joint network with different column irregularity

The mean side length of the column isdefined as the $b$ value $b$ in Fig. 3 . The range of $b$ was determined within $[0.1,0.5] \mathrm{m}$ according to the most common size of the type I and type II columnar jointed rock mass, who are the most important study subjects in this paper.

For loading directions in the anisotropic characteristics, in order to reflect the difference significantly, two orthogonal loading direction were selected. And for the convenience of discussion, they will be referred as $x$ axis and $y$ axis, as shown in Fig. 3.

As for the mechanical parameters of rock matrix and joints, recommended values were gained via experience and indoor tests, as shown as the standard values in Tab. 1. Other test values are also shown in Tab.1.

(1) Longitudinal plane

Table 1 Mechanical parameters of rock and joints

\begin{tabular}{ccccc}
\hline Materials & $\begin{array}{c}E \\
(\mathrm{GPa})\end{array}$ & $v$ & $\begin{array}{c}K_{\mathrm{n}} \\
(\mathrm{GPa} / \mathrm{m})\end{array}$ & $\begin{array}{c}K_{\mathrm{s}} \\
(\mathrm{GPa} / \mathrm{m})\end{array}$ \\
\hline Rock matrix & 60 & 0.2 & - & -- \\
Joint(standard values) & -- & -- & 40 & 15 \\
Joint(lower values) & -- & -- & 10 & 3.75 \\
Joint(sub-lower values) & -- & -- & 20 & 7.5 \\
Joint(sub-higher values) & -- & -- & 60 & 22.5 \\
Joint(higher values) & -- & -- & 80 & 30 \\
\hline
\end{tabular}

As for the longitudinal plane, the nature of the joints on this plane is the combination of two orthogonal sets. One is regularly developed penetrated joint set, the other is a set of non-penetrated joint. For the sake of distinction, they are called joint set one and two, respectively, as shown in Fig 4. According to the formula of equivalent modulus of rock mass containing parallel developed discontinuous, spacing of joint set one $\left(s_{1}\right)$ has nothing to do with rock mass. Hence the representative index of structure effect on this plane are merely spacing of joint set two $\left(s_{2}\right)$ and "stairway ratio" $\left(L / s_{2}\right)$, their respective definitions can be found in Fig. 4.

Range of spacing of joint set two is set as $[0.6,1.8] \mathrm{m}$ according to field measurement for type I and type II columnar jointed rock mass. Two examples with different $s_{2}$ are shown in Fig. 6.

Range of the stairway ratio is set as [0,100\%], two examples can also be found in Fig. 7.

The mechanical parameters of rock matrix and joints are also studied for longitudinal plane; their range are the same as that in Tab. 1. 


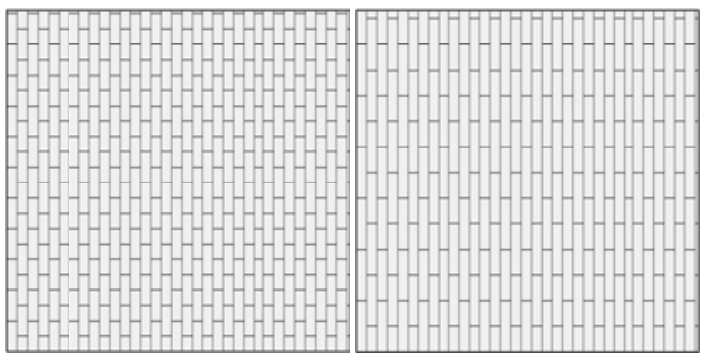

(a) $\mathrm{s} 2=0.9 \mathrm{~m}$ (b) $\mathrm{s} 2=1.5 \mathrm{~m}$

Fig. 6 Joint network with different $s_{2}$

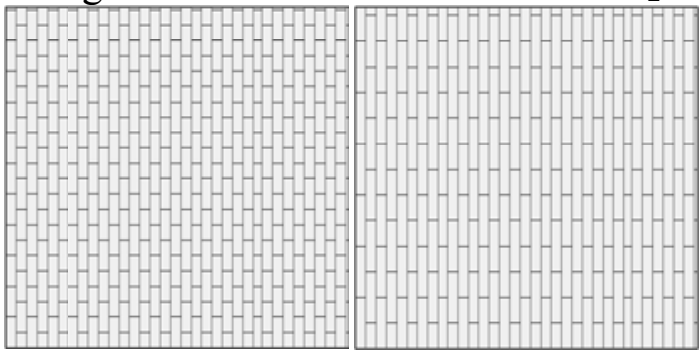

(a) $\mathrm{s} 2=0.9 \mathrm{~m}$ (b) $\mathrm{s} 2=1.5 \mathrm{~m}$

Fig. 7 Joint network with different $L / s_{2}$

\section{Structural effect on equivalent elastic modulus}

In the following contents, for the sake of clearness and conciseness, univariate research method was adopted, i.e., changing only the current study index, leave other indexes untouched.

Hence, for the transverse plane, unless otherwise mentioned, basic numerical conditions are as follows: mean side length of the column is $0.3 \mathrm{~m}$, loading direction is $y$, mechanical parameters of rock mass are the standard values.

Similarly, for the longitudinal plane, basic numerical conditions are as follows: $s_{1}=0.3 \mathrm{~m} ; s_{2}=0.3 \mathrm{~m}$; mechanical parameters of rock mass are the standard values.

\section{Transverse plane.}

(a) Column irregularity

Fig. 8 gives equivalent elastic modulus of different column irregularity. Due to the randomness nature brought upon by the Voronoi possess, 10 samples of were generated are analyzed for each case, and their average value is taken as the equivalent elastic modulus under present characteristic parameter.

Results from Fig. 8 can be summarized as more irregular the column is, more the corresponding equivalent elastic modulus would be. Difference between the equivalent elastic modulus of fully regular case and irregular case would be at a level of $10 \%$.

From a mechanical point of view, this phenomenon can be explained as follows: more irregularity of the column means a higher occlusion level between the columns. This leads to a low sliding ability between columnar joints, and a correspondingly higher equivalent elastic modulus.

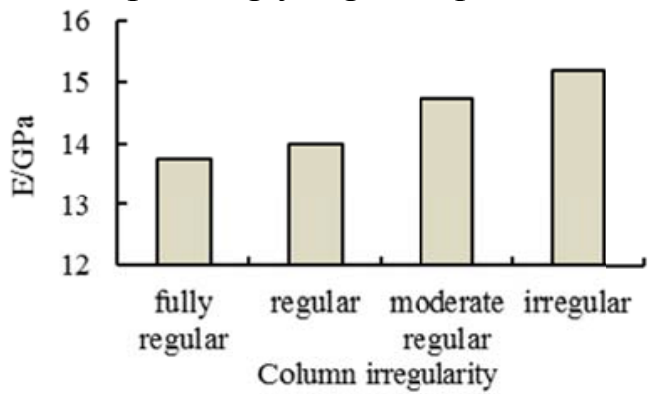

Fig. 8 Equivalent elastic modulus of different column irregularity

(b) Side length of the column

Fig. 9 gives equivalent elastic modulus of different mean side length of column. Again, due to the randomness nature brought upon by the Voronoi possess, 10 samples of were generated are analyzed 
for each case, and their average value is taken as the equivalent elastic modulus under present characteristic parameter.

From a mechanical point of view, this phenomenon can be explained as follows: as the increase of the mean side length, the total number of joints in the rock mass decrease, resulting the strengthen of the rock mass. This phenomenon agrees the fact that type III columnar jointed rock mass whose size is bigger than the type I columnar jointed rock mass owns better mechanical properties $[11,12]$.

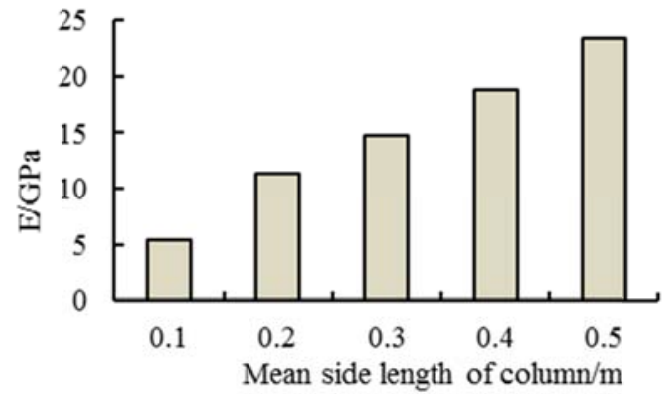

Fig. 9 Equivalent elastic modulus of different mean side length of column

(c) Loading direction

In the previous works, $y$ direction is taken as the loading direction. The question that whether the transverse plane can be treated isotopically is not yet answered. Here, the results corresponding to loading from $x$ axis is presented in Fig. 10 and Fig. 11. The deference in result from each loading direction is merely $-0.64 \sim 0.5 \mathrm{GPa}$, or $3 \%$ in a percentage terms.

In this manner, jointed columnar rock mass can be treated as isotopic on the transverse plane. And this Isotropic characteristic will not be influenced by column irregularity or columnar size.

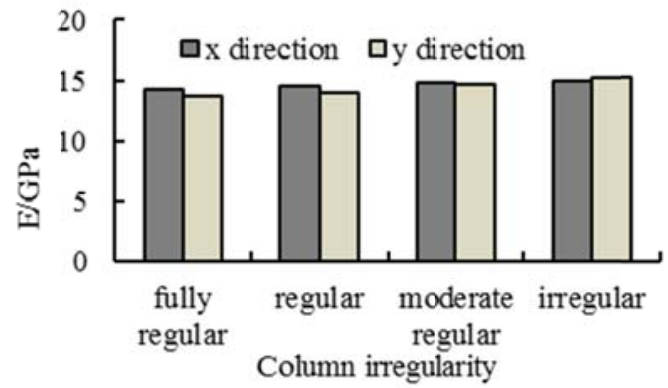

Fig. $10 x$-direction modulus vs. $y$-direction modulus of different average column size

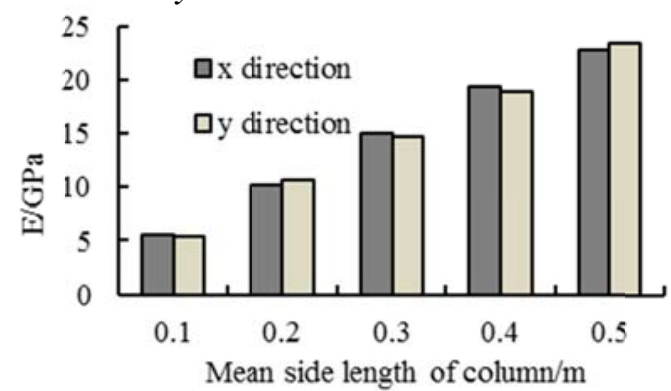

Fig. $11 x$-direction modulus vs. $y$-direction modulus of different average column size (d) Joint stiffness

Fig. 12 shows the equivalent elastic modulus of different joint stiffness. Results confirmed that the equivalent elastic modulus increases linearly with the joint stiffness. Further investigation shows this linear trend will not affect by variety of column irregularity or columnar size. 


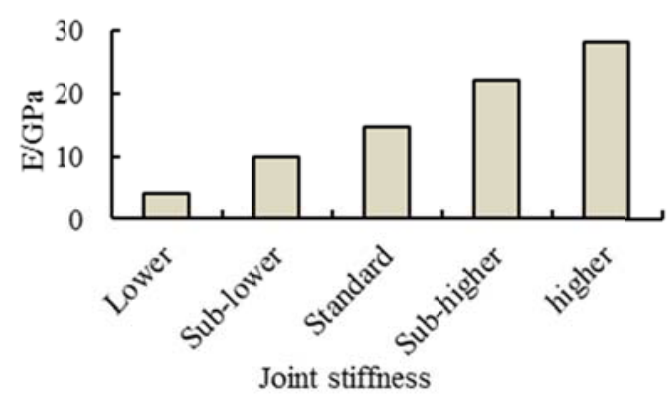

Fig. 12 Equivalent elastic modulus of different joint stiffness

\section{Longitudinal plane}

(a) Spacing of joint set two

Fig. 12 shows the equivalent elastic modulus of different spacing of joint set two $\left(s_{2}\right)$. Results confirmed that equivalent elastic modulus increases with $s_{2}$.

As comparison, a theory solution of jointed rock mass with $50 \%$ penetration was given in Fig. 13 , in accordance with the theory of equivalent modulus of jointed rock mass $[9,10]$. Despite the little differences in magnitude, the trend is almost the same.

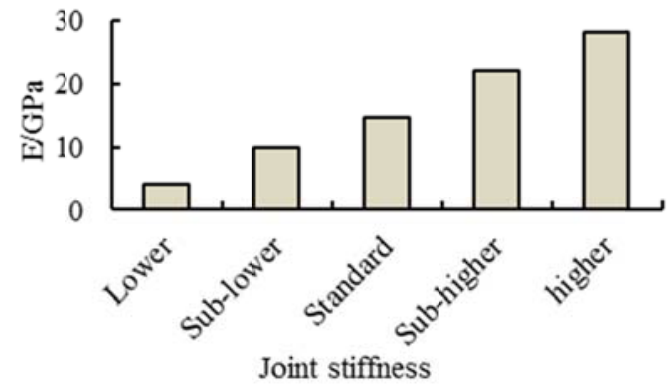

(b) Stairway ratio

Fig. 13 Equivalent elastic modulus of different $s_{2}$

The influence of stairway ratio on the equivalent elastic modulus was shown in Fig. 14. Clearly, the equivalent elastic modulus reaches its largest value as the stairway ratio is $50 \%$. Difference between the equivalent elastic modulus of lowest and largest stairway ratio case would be at a level of $10 \%$.

From a mechanical point of view, the reason why the equivalent elastic modulus reaches its largest value as the stairway ratio is $50 \%$ can be given as the columns get their most occlusion. Ref. [13] gained a same conclusion based on composite mechanic's theory.

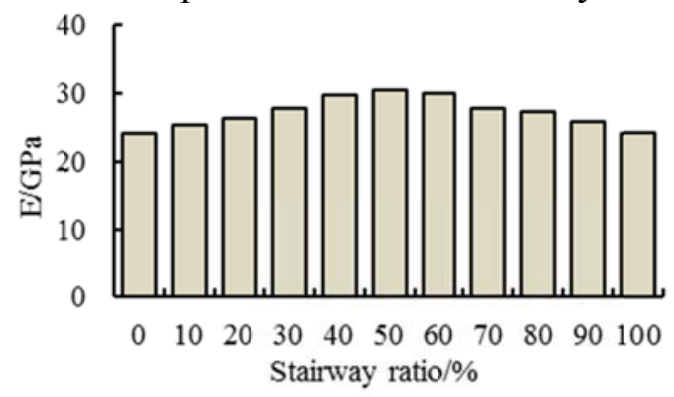

(c) Joint stiffness

Fig. 14 Equivalent elastic modulus of different $s_{2}$

Fig. 15 shows the equivalent elastic modulus of different joint stiffness. Results confirmed that the equivalent elastic modulus increases linearly with the joint stiffness. Again, further investigation shows this linear trend will not affect by variety of column irregularity or columnar size. 


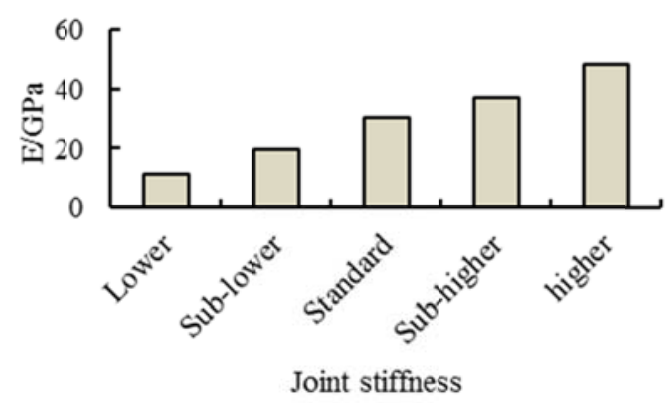

Fig. 15 Equivalent elastic modulus of different joint stiffness

\section{Comparison with existing results}

To illustrate the methods used in this paper and to ensure the credibility of the conclusions of the study, research results in Ref. [14] were compared.

Ref. [14] used the $3 \mathrm{~d}$ discrete element method and also the Voronoi possess to generate the columnar jointed rock mass, as a tool to investigate the scale effect of equivalent elastic modulus of the columnar jointed rock mass.

The type II columnar jointed rock mass was take as the comparison item, as shown in Tab. 2 . Additionally, in situ study results are also from Ref. [14].

Comparison result confirmed the validation of the methods and research insights of this paper. Table 2Research results analysis

\begin{tabular}{|c|c|c|c|}
\hline \multirow[b]{2}{*}{ Source } & \multicolumn{2}{|c|}{ Modulus on transverse plane /GPa } & \multirow{2}{*}{$\begin{array}{c}\text { Modulus on } \\
\text { longitudinal plane } \\
/ \mathrm{GPa}\end{array}$} \\
\hline & direction 1 & direction 2 & \\
\hline In situ study results & 13.24 & 13.22 & 41.05 \\
\hline Ref.[14] & 13.67 & 14.13 & 39.92 \\
\hline This article & 14.99 & 14.73 & 30.49 \\
\hline
\end{tabular}

\section{Summary}

In this paper, influence of structural effect on the equivalent modulus of columnar jointed rock mass is discussed via Jointed Finite Element technique for the Baihetan project. Findings of this paper can be summarized as

(1) On the transverse plane, more the irregularity of the column is, the higher the equivalent modulus is. And this trend also aggresses with the increase of the column size. Columnar joints rock mass can be regarded as isotropic in the transverse plane. As the joint stiffness linearly increase, the equivalent modulus corresponding basically with the linear increasing.

(2) As for the longitudinal plane, more the spacing of the joint set II, the higher the equivalent modulus is. The equivalent modulus reaches its maximum value when the stagger ratio is $50 \%$. Like on the transverse plane, as the joint stiffness linearly increase, the equivalent modulus linearly increases, correspondingly.

(3) The results of this paper agree well the existing field observations and 3-d numerical studies. The findings and conclusions of this paper may provide a reference for future studies.

\section{Acknowledgements}

The study was financially supported by the National Basic Research Program of China (No. 2015CB057905), and National Natural Science Foundation of China, (Nos. 51409263, 11472292).

\section{References}

[1] Gu De-zhen. Rock engineering Geomechanics Foundation[M]. Beijing: Sicience press, 1979.

[2] Sun Guang-zhong. Structural rock mechanics[M] . Beijing: Science press, 1988. 
[3] JIANG Quan, FENG Xia-ting,FAN Yi-lin, et al. survey and laboratory study of anisotropic properties for columnar jointed basaltic rock mass[J]., 2013, 32(12): 2527-2536.

[4] SHI An-chi, TANG Ming-fa,ZHOU Qi-jian. Research of deformation characteristics of columnar jointed basalt at baihetan hydropower station on jinsha river[J]. Chinese Journal of Rock Mechanics and Engineering, 2008, 27(10): 2079-2085.

[5] LU Yi-ran. Deformation Anisotropy study of columnar jointed rock masses[D]. Wuhan: Yangtze Scientific Institute, 2010.

[6] Itasca Consulting Group Inc.. UDEC (Universal Distinct Element Code) Background-The 2D Distinct Element Method (version 6.0)[R]. Minneapolis: Itasca Consulting Group Inc., 2014.

[7] RocscienceInc.. Phase2 Joint Network Verification[R]. Toronto, Ontario: Rocscience Inc., 2011.

[8] NING Yu, XU Wei-ya, ZHENG Wen-tang, et al. Study of random simulation of columnar jointed rock mass and its representative elementary volume scale[J]. Chinese Journal of Rock Mechanics and Engineering, 2008, 27(6): 1202-1208.

[9] Zhang Zhan-rong. Study on deformation properties of fractured rock mass[D]. Wuhan: Institute of Rock and Soil Mechanics, Chinese Academy of Sciences, 2010.

[10]J. C. Jaeger, N. G. W. Cook, R. Fundamentals of Rock Mechanics (3 ${ }^{\text {rd }}$ ed.)[M]. London: Chapman and Hall, 1979.

[11]XU Wei-ya, ZHENG Wen-tang, SHI An-chi. Classification and quality assessment of irregular columnar jointed basaltic rock mass for hydraulic engineering[J]. Hydraulic Journal, 2011, 42(3): 262-271.

[12]Zhang Chun-fang. BaiheJinsha River Hydropower Station columnar joints basalts rockmass structural and quality classification[D]. Chengdu: Chengdu University of Technology, 2008.

[13]DI Sheng-jie, XU Wei-ya, WANG Wei, et al. Transversely isotropic constitutive properties of a columnar jointed rock mass[J]. Journal of China University of Minim \& Technology, 2011, 40(6): 881-888.

[14] YAN Dong-xu, XU Wei-ya, WANG Wei, et al. Research of size effect on equivalent elastic modulus of columnar jointed rock mass[J]. Chinese Journal of Rock Mechanics and Engineering, 2012, 34(2): 243-251. 